\title{
O uso de um simulador para práticas de Redes de Computadores em um modelo de Ensino Remoto Emergencial
}

DOI: 10.37702/2175-957X.COBENGE.2021.3553

Otacílio José Pereira - otacilio.pereira@ifsudestemg.edu.br Instituto Federal do Sudeste de Minas Gerais

Av JK 20

36909-300 - Manhuaçu - MG

Raphael Tavares Vermelho - raphaelvermelho@gmail.com IFSUDESTEMG

Rua Tiradentes 21

36700-056 - Leopoldina - MG

Resumo: Este trabalho relata uma experiência de uso de um simulador para uma disciplina de redes de computadores diante da inviabilidade de aulas presenciais em laboratórios por conta da pandemia por Covid-19. Além de lidar com um modelo de Ensino Remoto Emergencial (ERE), o professor tinha ainda outros desafios como o ensino em nova modalidade (ensino técnico) e em nova região e isso exigiu uma adoção prudente e bem planejada da tecnologia. De início o simulador foi um estudo de caso em uma matéria de Usabilidade de Sistemas em uma pós-graduação e depois ele foi aplicado na turma alvo do ensino técnico. Os resultados provenientes dos testes de usabilidade e de outras técnicas de experiência do usuário foram satisfatórios e apontam para um potencial de aplicação desta estratégia para minimizar perdas e explorar outras alternativas no processo de ensino e aprendizagem.

Palavras-chave: Simuladores, Redes de Computadores, Ensino Remoto Emergencial, Usabilidade 


\section{O uso de um simulador para práticas de Redes de Computadores em um modelo de Ensino Remoto Emergencial}

\section{INTRODUÇÃO}

A pandemia assolou diversos setores da sociedade com mudanças abruptas e isso provocou um processo de adaptação, por exemplo os negócios do ramo de alimentação precisaram adotar um formato de entrega em domicílio ("delivery") e comércios em geral viram alternativas no marketing digital e comércio eletrônico. Na educação, a tendência nas instituições de ensino foi migrar para o regime de ensino remoto emergencial que temporariamente usa um modo de ensino alternativo devido às circunstâncias de uma crise. Nesta mudança muitas eram as questões sobre como planejar e gerenciar cursos e disciplinas com a adaptação de conteúdos e práticas pedagógicas neste novo cenário.

O objetivo deste trabalho é apresentar um relato sobre a aplicação de um simulador em uma disciplina de Redes de Computadores para um curso técnico de informática de um instituto federal. Além do desafio de se adaptar ao regime de Ensino Remoto Emergencial (ERE), o professor precisava ainda lidar com o início em uma nova instituição, em uma região diferente e em uma modalidade de curso técnico. Antes o professor atuava em outra região do país e para o ensino superior. Por conta de todos estes pontos de atenção para gerir as mudanças, o professor considerou importante realizar um planejamento mais prudente e sistemático para o uso do simulador, seguindo etapas graduais de uso e com emprego teste de usabilidade e de técnicas de projeto de experiência do usuário (User Experience) no processo.

A seção 2 apresenta uma revisão bibliográfica para contextualizar temas sobre Ensino Remoto Emergencial e o uso de simuladores no ensino de redes de computadores ou de engenharia. A seção 3 descreve o cenário do relato de experiência e na seção 4 as estratégias para incorporar o simulador diante das diversas circunstâncias importantes são apresentadas. Por fim, as seções 5 e 6 apresentam os resultados e as considerações finais.

\section{REVISÃO BIBLIOGRÁFICA}

O trabalho tem relação com dois temas que vale explorá-los para uma melhor compreensão do relato. O primeiro é sobre o Ensino Remoto Emergencial que foi adotado no período de pandemia na instituição e o segundo discute o uso de simuladores no ensino de engenharia e especificamente neste caso para redes de computadores.

\subsection{Ensino Remoto Emergencial}

Diante do cenário de pandemia e suas demandas por transformações emergenciais em toda a sociedade, algumas das principais recomendações foi evitar aglomerações e aumentar os cuidados de higiene. Para atender estas orientações os setores adotaram as suas estratégias, por exemplo, restaurantes usaram os formatos de entrega em domicílio (delivery) ou de apenas passar e pegar as encomendas (drive-thru). Na educação, limitar a oportunidade do encontro atinge o cerne do ensino presencial que pressupõe alunos e professores juntos em uma sala de aula ou laboratório. Para práticas com equipamentos físicos isso é ainda mais crítico pois alguns dos modelos com disponibilização de videoaulas e exercícios são mais limitados do que o manusear de ferramentas e máquinas.

Observando a forma como as instituições pensaram e reagiram, vários caminhos foram adotados e em cada tempo. Existiram escolas que mudaram abruptamente e corrigiram rotas no curso das ações. Outras suspenderam atividades acadêmicas para 
aguardar o retorno por sensibilidade a graves cenários de exclusão digital. O longo tempo e ausência de melhores perspectivas mobilizaram a adoção de algum modelo temporário. Independente dos caminhos, existiam significativas incertezas e inseguranças além de dificuldades e adaptações quanto às normativas.

Nesse cenário, naturalmente o ensino a distância (EaD) surgiu como caminho e neste ponto vale uma distinção do EaD com o formato que foi adotado de Ensino Remoto Emergencial (ERE). Conforme Hodges et al. (2020), "o Ensino Remoto Emergencial (ERE) é uma mudança temporária para um modo de ensino alternativo devido a circunstâncias de uma crise como guerras, desastres naturais e epidemias". Há uma diferença relevante, na $\mathrm{EaD}$ há toda uma organização para ofertar os cursos com equipes multidisciplinares: professores conteudistas, designers, revisores, dentre outros, e tudo feito em uma curva de aprendizado mais confortável. No ERE, ainda conforme Hodges et al. (2020), "o foco não é recriar todo um ecossistema robusto de oferta do ensino, em vez disso a intenção é fornecer acesso temporário às instruções de maneira rápida de configurar e disponível de maneira confiável durante a emergência". A EaD serve de norte porém é provável que não haverá uma estrutura tão robusta disponível.

Discussões pedagógicas foram também variadas e com decisões muitas vezes pautadas muito por conhecimento tácito. Alguns professores imaginavam uma transformação literal da aula para uma versão virtual síncrona com problemas de adoção por causa do pacote de dados dos alunos e limites de concentração em videoaulas longas. Outros recorreram a guias de boas práticas, usavam vídeos curtos e ferramentas diversas e existiam ainda os que consideraram inviável qualquer adaptação. Um ponto importante muito discutido em comissões e colegiados foi sobre as aulas práticas e neste caso havia maior concordância pela dificuldade em substituir os laboratórios presenciais.

O caminhar por esse aprendizado enquanto se adotam medidas contingenciais já gerou experiências relatadas com o ERE. Matta (2020) apresenta percepções de alunos e professores na adoção do Regime de Tratamento Excepcional em cursos de engenharia, equivalente ao ERE aqui apresentado. Nesse trabalho eles comentam que os alunos apontaram pontos positivos como a possibilidade de dar prosseguimento aos estudos e sentir-se produtivo, entretanto pontos negativos foram apontadas por uma boa parte, o caso de conciliar os estudos com tarefas domésticas. Quanto aos professores, o que chamou a atenção dos autores foi que uma pequena parte dos professores (10\%) usaram ambientes interativos ou simuladores o que indicou que a estratégia adotada foi de replicar a aula presencial para o modelo remoto e sem explorar uma postura mais ativa dos alunos.

\subsection{Simuladores no Ensino de Engenharia}

O uso de simuladores em processos de aprendizagem em engenharia já é disseminado. Guoqiang (2010) comenta que a rápida melhoria do desempenho de computadores serve de base para implementação de diversas tarefas de grande escala e que a simulação por computador é uma importante vertente da tecnologia computacional usada na educação.

Em geral os benefícios do uso de simuladores são a redução de investimentos em laboratórios físicos, a economia de materiais de consumo para experiências práticas e a redução de riscos em tarefas perigosas que requerem uma plena competência do aprendiz. Um exemplo ilustrativo que demonstraria estes benefícios é o uso de simulador na formação de pilotos de avião, esse uso economiza o investimento em aeronaves, o consumo de combustível é otimizado e erros do piloto não provocam consequências graves. Outro argumento para se usar simulação é o fato de tornar a aprendizagem mais interessante. 
Alguns exemplos de trabalhos ilustram estes benefícios. Silva (2020) relata a construção de um simulador de um reator de pesquisa presente em um Centro de Desenvolvimento de Tecnologia Nuclear que permite explorar conceitos sobre reatores nucleares tornando o "aprendizado uma tarefa mais prazerosa e engajadora". Em Farias et al (2020) situações arriscadas na área de eletrônica de potência são gerenciadas proporcionando uma evolução gradual do aprendizado através de recursos educacionais do NI Multisim Live e PSIM.

Enfim, a educação em engenharia e até mesmo o exercício das atividades profissionais podem usufruir de lidar com situações simuladas para uma melhor compreensão de um cenário, maior efetividade nas decisões, economia de recursos, segurança e um aprendizado mais prazeroso e engajador. No caso da experiência neste trabalho, além destes benefícios mais disseminados, o uso do simulador foi uma alternativa para um modelo de educação remota em que o acesso aos laboratórios é limitado.

\subsection{Simuladores de Redes de Computadores e o Cisco Packet Tracer}

Do mesmo modo que na engenharia e em outras áreas, também na tecnologia e especificamente em redes de computadores existem os simuladores para apoiar o processo de ensino e aprendizagem. Conforme Silva et al. (2019) estes softwares são usados sobretudo quando há limitações em infraestrutura de laboratórios e equipamentos, e alguns exemplos destes simuladores são: CORE, NetKit, OMNet++ e o Cisco Packet Tracer.

Uma opção que se mostrou interessante nesta experiência foi o Cisco Packet Tracer por conta de ser oferecido gratuitamente pela Cisco, uma empresa reconhecida na área pelos seus equipamentos e pelo seu programa de certificação profissional (CISCO NETWORKING ACADEMY, 2021). Em Silva et al. (2019) esse simulador foi experimentado com bons resultados mas com ressalvas quanto à interface que poderia ser mais simples. De fato, por ser muito completo, ele exige mais do usuário por conta de vários tipos de equipamentos e janelas, pelos comandos e outros recursos que oferece.

Para o cenário deste relato havia uma preocupação quanto ao nível dos alunos para acomodar a tecnologia, sobretudo remotamente. Em uma nova pesquisa encontrou-se uma versão mais simples do simulador, o PT Anywhere (Figura 1) em que PT é uma abreviação de Packet Tracer e esta alternativa tem uma interface muito mais enxuta e intuitiva além de ser disponibilizada na Web (online), portanto sem necessidade de instalação (MIKROYANNIDIS et al., 2018). Estes fatores apontavam uma maior facilidade para incorporar a simulação na disciplina.

Figura 1 - Simulador PT (Packet Tracer) Anywhere

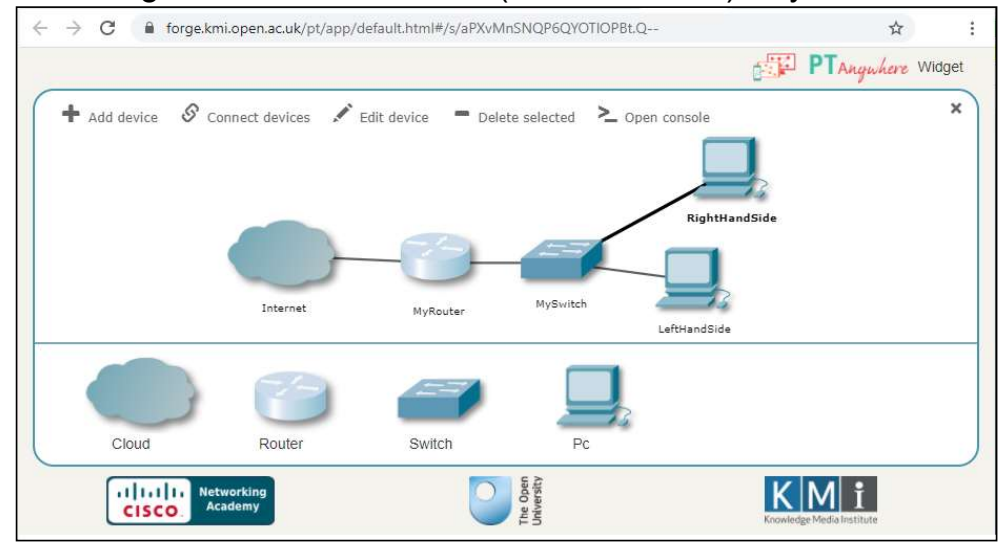

Fonte: (PT ANYWHERE, 2021) 


\section{CENÁRIO DE APLICAÇÃO}

Essa experiência ocorreu em uma disciplina de Redes de Computadores I de um curso técnico em informática concomitante ou subsequente de um instituto federal no interior de Minas Gerais. O objetivo da disciplina é apresentar alguns aspectos teóricos, o funcionamento básico e procedimentos de montagem de uma pequena rede local.

A turma continha 10 alunos pois alguns outros, ao partir para o ensino remoto, preferiram trancar o curso e aguardar o retorno ao modelo presencial. Na implantação do ERE a instituição avaliou se os alunos teriam acesso a computador e internet e lançou um programa de assistência para aquisição para os que atendiam alguns critérios. Assim, todos os alunos, alguns de zona rural, podiam acompanhar as aulas pela Internet sem a necessidade, por exemplo, de recursos impressos. De acordo com as regras do ERE o professor poderia optar por ofertar apenas parte da carga horária e daí apenas $50 \%$ foi ofertada no regime do ERE para tratar, a princípio, assuntos teóricos e independentes da infraestrutura física. Depois, com o retorno das aulas presenciais, a disciplina será complementada com as práticas em laboratório.

\section{$4 \quad$ O USO DO SIMULADOR NA DISCIPLINA}

Durante o planejamento da disciplina e refletindo sobre seus assuntos, algumas alternativas foram pensadas para contornar a dificuldade com o ensino prático. Isso ocorreu sobretudo ao decompor os capítulos e tópicos e identificar seus objetivos, sabendo-se que as restrições de ida à instituição eram apenas para os alunos, uma primeira estratégia imaginada foi o professor ir aos laboratórios, gravar vídeos das práticas e daí os alunos exercitariam algumas reflexões. Nestas reflexões surgiu a ideia de adotar pois daí seria possível explorar algumas tarefas, ainda que virtualmente. Não seria possível exercitar a habilidade manual e a vivência, mas já seria possível fazer algumas equivalências das configurações lógicas. Por exemplo, o aluno precisaria entender os passos para montar uma rede e daí, adicionar, dispor e conectar os equipamentos, escolher as portas nas conexões, nomear e fazer as configurações IP e ao final realizar testes, identificar e resolver problemas. $\mathrm{E}$ isso ainda poderia ser conciliado com o suporte de vídeos do laboratório real para melhorar a equivalência.

Um ponto de atenção ao inserir o simulador como prática pedagógica seria lidar com a dificuldade que alguns alunos poderiam ter com a instalação e manuseio dos recursos dos softwares mais avançados. Vale lembrar que o professor era novo na instituição, seria também um primeiro contato com aluno de ensino médio e ele tinha o relato de outros professores sobre a dificuldade dos alunos. $E$ tudo isso ainda com o agravante de ser feito remotamente com base no ERE. Portanto, uma incorporação de forma bem planejada do simulador era necessária.

Para isso, um primeiro passo foi pesquisar e usar um simulador mais simples com base na web e foi encontrado o Packet Tracer (PT) Anywhere apresentado na revisão bibliográfica. Ele já atenderia às atividades pretendidas com os alunos e com muito mais simplicidade em relação aos simuladores mais avançados. Um segundo passo ou ideia surgiu da integração com uma outra disciplina ministrada pelo professor sobre Usabilidade de Sistemas Web no curso de pós-graduação. Usar o simulador como um estudo de caso no capítulo de introdução seria bastante oportuno pois os alunos da pós-graduação aprenderiam os conceitos de design de experiência do usuário (User Experience) com um exemplo prático e em uma situação concreta. Além disso o professor poderia fazer uma primeira investigação sobre o uso do simulador em uma turma mais experiente e daí prever 
uma adoção mais sistemática na disciplina de Redes do curso técnico. Era um exercício de interdisciplinaridade entre dois cursos em que todos acabavam usufruindo do aprendizado.

Diante das estratégias concebidas, partiu-se para o planejamento e execução das ações que envolveram basicamente três atividades. A primeira foi a experiência com o simulador na disciplina da pós-graduação, em que os alunos experimentaram o simulador realizando um teste de usabilidade. As outras duas ações foram no curso técnico, em uma atividade o aluno realizou a montagem de uma rede local simples (semelhante à apresentada na Figura 1) e na outra atividade mais complexa já foi necessário configurar um roteador para comunicação entre duas ou mais redes.

\subsection{Avaliação prévia da usabilidade na disciplina da pós-graduação}

Para a atividade no curso de pós-graduação, no capítulo de Introdução, um contexto de uso foi apresentado usando personas fictícios e descrição de cenários justamente sobre a necessidade de um professor incorporar um uso de um simulador em uma disciplina de redes, era uma situação real do professor em outra disciplina servindo de estudo de caso para os alunos. Diante do exposto, os alunos precisariam realizar um teste de usabilidade com as tarefas de montar uma rede e em cada tarefa eles sinalizariam o nível de dificuldade e o tempo para executar a tarefa. Ao final de tudo eles responderiam um formulário sobre a percepção e satisfação com a experiência. No Quadro 1 estão apresentadas algumas amostras dos personas e da descrição de cenário. As fotos são fictícias extraídas de um site de disponibilização pública.

Quadro 1 - Personas e cenário do estudo de caso da disciplina de Usabilidade de Sistemas da pós-graduação

\begin{tabular}{l}
\hline Personas \\
Aline, 16 anos, é estudante \\
de ensino médio, vive com \\
mãe e 2 irmãos. Curte redes \\
sociais e gosta de ciências e \\
matemática. Apresenta \\
algumas dificuldades com \\
informática mas pensa em \\
seguir carreira na área.
\end{tabular}

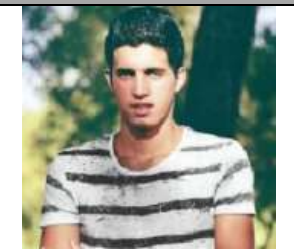

Jonelson, 20 anos, concluiu o ensino médio e trabalha na roça com o pai. Curte futebol e cavalos e tem dificuldade com informática. Identificado com a família e sua propriedade, pensa ampliar os negócios no campo nos próximos anos.

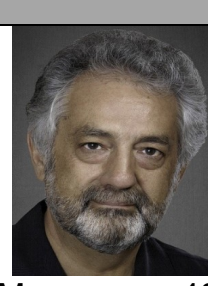

João Marcos, 48 anos, professor, atuou por 12 anos no ensino superior e há 6 meses iniciou em um curso técnico em informática. Ministra Redes de Computadores e vive os desafios da educação frente a pandemia por Covid-19.

\section{Descrição do cenário}

- João Marcos é um professor de Redes de Computadores e, diante da impossibilidade de aulas presenciais, ele resolveu adotar o uso de um simulador para imitar as tarefas de montagem de uma rede local.

- Aline e Jonelson são alguns de seus alunos, de um curso técnico e com pouca experiência em computação e sobretudo com redes de computadores.

- O tópico a explorar no simulador é de montagem e configuração de uma rede com o protocolo TCP/IP. O aluno após compreender o material da aula precisa realizar algumas tarefas, dentre elas: i) acessar/instalar o software simulador; ii) criar uma pequena rede e configurar os números IP's das máquinas; iii) testar a comunicação entre os computadores via comandos, por exemplo o "ping".

Fonte: Próprio autor

Com a compreensão dos personas e cenário, o aluno da pós-graduação precisava então realizar o teste de usabilidade seguindo um roteiro e em que cada tarefa ele registrava o resultado via uma cópia da tela, o nível de dificuldade e o tempo gasto. A Figura 1 mostra o resultado de uma das tarefas do roteiro em que o aluno precisa configurar os números 
IP's dos computadores. Perceba que na amostra da tela a rede se encontra ao fundo e uma tela de configuração dos IP's é mostrada em primeiro plano.

Figura 2 - Exemplo da realização de uma tarefa da experiência com o simulador

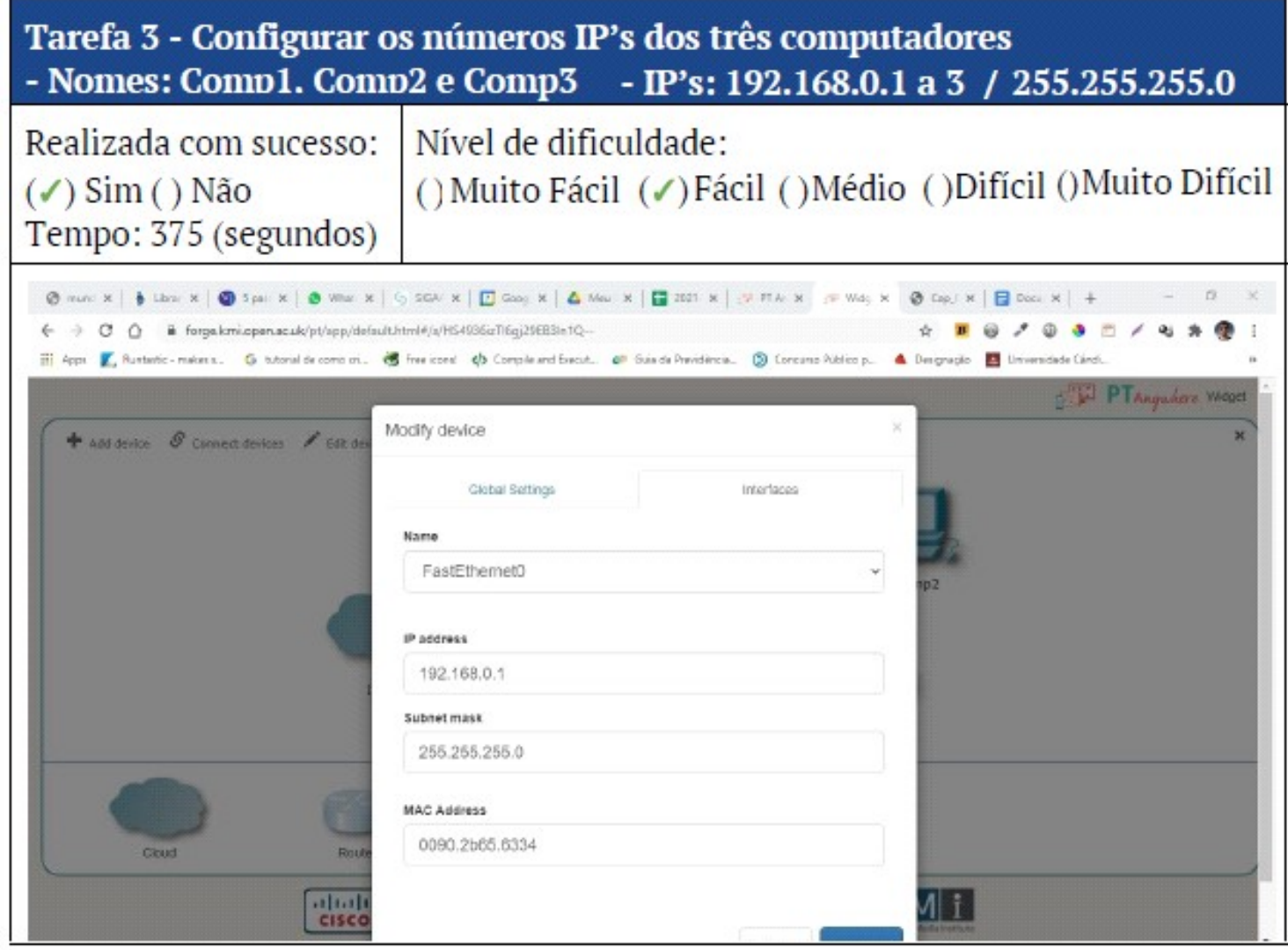

Fonte: (Próprio autor, amostra da tela obtida de (PT Anywhere, 2021) )

Após realizar todas as tarefas da experiência, o usuário fazia uma avaliação de usabilidade através do questionário SUS (System Usability Scale) criado por John Brooke em 1986. Esse questionário é bastante popular por conta de sua simplicidade e agilidade para aplicar e apesar disso, os resultados já permitem bons diagnósticos (SAURO e LEWIS, 2012). Este mesmo questionário foi replicado depois para a turma do curso técnico e o Quadro 2, mostrado ao relatar a experiência no curso técnico, apresenta algumas das perguntas da Avaliação de Percepção do aluno ou usuário que era preenchido logo após realizar o teste com as tarefas.

\subsection{Primeira experiência na disciplina do curso técnico}

Esta experiência no curso de pós-graduação serviu de base para os testes na turma do curso técnico com algumas tarefas adicionais, mas mantendo a essência de montagem de uma pequena rede. Neste caso não foram apresentados os personas nem o cenário foi descrito pois agora tratava-se de concretizar o que foi experimentado antes, na pósgraduação. As amostras de tela junto com a avaliação de percepção também eram produzidas pelos alunos, eles portanto praticavam ainda que virtualmente os procedimentos e com os dados levantados de níveis de dificuldade e satisfação era possível gerenciar a incorporação do simulador. Assim como ocorreu na pós-graduação, os alunos faziam uma avaliação da usabilidade através do questionário System Usability Scale (SUS) com algumas amostradas das perguntas mostradas no Quadro 2. 
Quadro 2 - Amostra de perguntas do questionário SUS (SAURO e LEWIS, 2012)

\begin{tabular}{|c|c|c|c|c|c|}
\hline \multirow{2}{*}{ Questões } & $\begin{array}{l}\text { Discordo } \\
\text { Completamente }\end{array}$ & Discordo & Neutro & Concordo & $\begin{array}{l}\text { Concordo } \\
\text { Totalmente }\end{array}$ \\
\hline & 1 & 2 & 3 & 4 & 5 \\
\hline \multicolumn{6}{|c|}{$\begin{array}{l}\text { 4. Achei que seria necessário um técnico para } \\
\text { poder usar este sistema }\end{array}$} \\
\hline \multicolumn{6}{|c|}{ 5. Eu me senti confiante ao usar este sistema } \\
\hline \multicolumn{6}{|c|}{$\begin{array}{l}\text { 7. Imagino que a maioria dos alunos usariam } \\
\text { este sistema com facilidade }\end{array}$} \\
\hline \multicolumn{6}{|l|}{$\begin{array}{l}\text { 9. Foi fácil encontrar a informação que eu } \\
\text { precisava }\end{array}$} \\
\hline 10. A interface do sistema é agradável & & & & & \\
\hline
\end{tabular}

Fonte: (Próprio autor)

\subsection{Segunda experiência no curso técnico explorando roteamento entre redes}

Além da montagem de uma rede simples, no curso técnico houve ainda uma segunda experiência sobre o roteamento entre duas redes com uma estrutura semelhante à mostrada na Figura 3. Esta experiência não foi experimentada na pós-graduação, pretendia-se apenas avaliar o primeiro passo de incorporação e não queria na disciplina com outro foco explorar mais assuntos de redes de computadores. Mas no curso técnico, já que o primeiro passo tinha sido consistente, nesta experiência o aluno precisaria realizar mais tarefas e mais complexas como: i) montar as duas redes; ii) acrescentar um roteador e conectá-lo aos switches de cada uma das redes; iii) configurar o roteador e suas portas via linhas de comandos; iv) configurar o "gateway padrão" nos computadores das redes locais e; v) por fim testar se as "redes se comunicavam". Um destaque nesta atividade é que a configuração do roteador não era feita com o apoio de telas gráficas, era necessário usar comandos de linha como "interface gigabitethernet0/1" e "ip route" para tratar as interfaces e os rotas estáticas, respectivamente. Nesta segunda experiência, os alunos não respondiam sobre a percepção de uso do simulador pois já tinham respondido antes e o nível de dificuldade foi avaliado pela própria correção das tarefas.

Figura 3 - Estrutura da experiência 2 com duas redes e um roteador

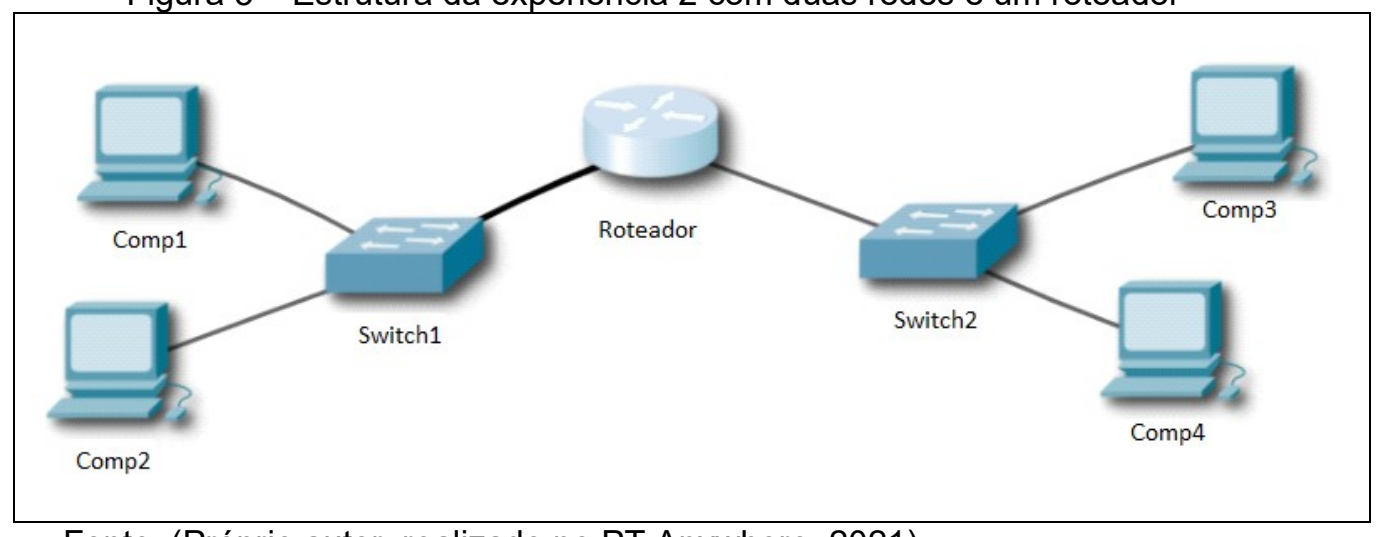

Fonte: (Próprio autor, realizado no PT Anywhere, 2021) 


\section{$5 \quad$ ANÁLISE DOS RESULTADOS}

Em todas as experiências foram levantados dados para análise das ações. Na montagem e configuração de uma rede local, tanto na pós-graduação como no curso técnico, foram usados os dados sobre o nível de dificuldade e tempo na realização das tarefas bem como as respostas de percepção do usuário ao final da experiência. $\mathrm{Na}$ experiência com o roteamento entre redes, os dados usados foram de correção dos trabalhos, tarefa por tarefa ao montar a rede no simulador. Na turma da pós-graduação eram 3 (três) alunos envolvidos e a turma do curso técnico continha 10 (dez) estudantes.

\subsection{Resultados da experiência preliminar da disciplina da pós-graduação}

Os dados da experiência na pós-graduação sobre nível de dificuldade das tarefas estão apresentados no Quadro 3. Percebe-se que há uma predominância de respostas fácil e muito fácil e apenas a tarefa de configuração dos números IP das máquinas teve respostas em nível médio e difícil. Vale lembrar que neste caso não foram apresentadas aulas ou conceitos de redes e ainda assim os resultados foram bem favoráveis. Este panorama deu uma tranquilidade para a adoção do ambiente no curso técnico com alguma atenção para a tarefa de configuração de números IP.

Quadro 3 - Resultados no nível de dificuldade na experiência com a pós-graduação

\begin{tabular}{|l|c|c|c|c|c|}
\hline Tarefa & Muito Fácil & Fácil & Médio & Difícil & Muito Difícil \\
\hline 1. Acesso ao ambiente & 3 & & & & \\
\hline 2. Adição de computadores & 1 & 2 & & & \\
\hline 3. Configuração de IP's & & 1 & 1 & 1 & \\
\hline 4. Testes de conectividade & 1 & 2 & & & \\
\hline
\end{tabular}

Fonte: (Próprio autor)

\subsection{Resultados da primeira experiência (rede simples local) no curso técnico}

Para o curso técnico, a Figura 4 apresenta os dados da percepção de dificuldade para as 7 tarefas previstas desde uma ambientação inicial, criação da rede, configurações e testes finais em que cada aluno podia responder entre muito fácil, fácil, médio, difícil e muito difícil. Lembrando que neste caso algumas tarefas foram adicionadas.

Nas tarefas iniciais (T1, T2 e T3) predominam as respostas em nível fácil ou mesmo muito fácil. Já a partir da tarefa T4 que envolve a lógica de configuração de números IP e testes da rede, as respostas predominantes são de nível médio. Esta percepção coincidiu em certa forma com os resultados da pós-graduação ao indicar maior dificuldade do aluno ao lidar com tarefas que exigem maior compreensão da lógica de funcionamento e que sobretudo exigem que "se faça a rede funcionar". Pela simplicidade do simulador imaginava-se obter boas respostas com níveis baixos de dificuldade o que foi comprovado para tarefas iniciais e com níveis um pouco mais alto para as tarefas finais. No geral os dados apontam que ficou confortável o uso para os alunos.

Outra informação relevante, apenas 7 dos 10 alunos entregaram a atividade, os outros 3 justificaram por conta de dificuldade com entender a lógica e com o fazer funcionar o experimento. Interessante observar que atingir este objetivo do aluno compreender melhor a lógica do funcionamento da rede seria difícil apenas com uma estratégia de vídeos demonstrativos em laboratório. 
Figura 4 - Resultados da percepção de dificuldade na primeira experiência no curso técnico

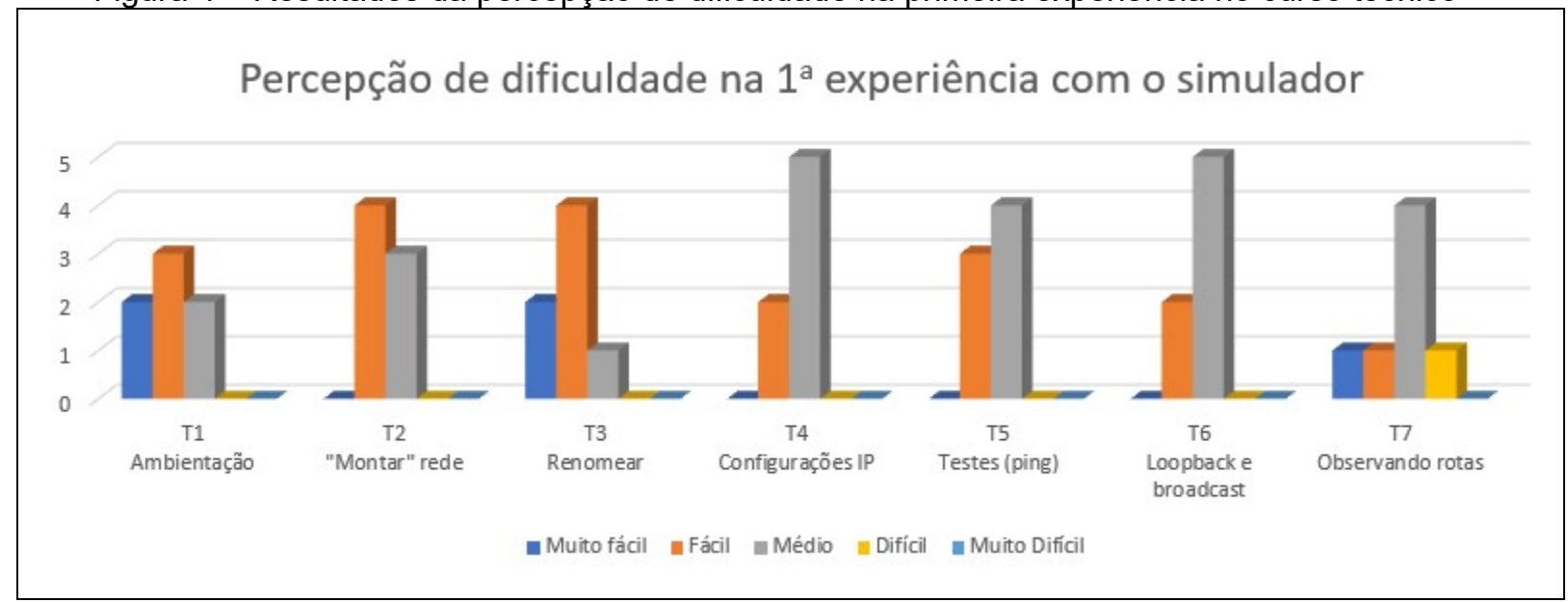

Fonte: (Próprio autor)

\subsection{Segunda experiência (roteamento entre redes) no curso técnico}

$\mathrm{Na}$ segunda experiência que exigia a configuração de roteamento entre duas redes, apenas 5 alunos entregaram a atividade e dentre eles o rendimento na correção das tarefas foi em média de $61 \%$. Estes resultados de desempenho (em percentual da nota máxima) e a quantidade de entregas foram comparados com o desempenho em outras atividades em outros capítulos e estão mostrados no Quadro 4. Importante lembrar que cada aluno tinha seu respectivo tema ou conjunto de parâmetros em cada avaliação para dificultar eventuais cópias de trabalhos ou outros meios não apropriados.

Os capítulos iniciais, com predominância de avaliação como listas de exercícios e trabalhos escritos tiveram resultados melhores com maior número de entregas e com rendimento melhor. A atividade simples com o simulador, teve menos entregas mas com bom rendimento bom e a atividade mais desafiadora com roteamento teve entregas e rendimento inferiores. A média do desempenho foi feita considerando apenas os trabalhos entregues, as notas zeradas por falta da entrega não interferiram na média do desempenho. No capítulo 5 a atividade foi simples, uma explicação de alguns dos protocolos das camadas mais altas, por isso os resultados compatíveis com os capítulos iniciais, menos desafiadores. O resultado mais baixo na experiência com o roteador pode ter duas causas, ou a tarefa de fato foi mais desafiadora com mais tarefas complexas e comandos de linha por exemplo, ou a causa foi que o prazo coincidiu com a data de entrega de outras atividades de outras disciplinas e daí os alunos se dedicaram menos.

Quadro 4 - Resultados do desempenho dos alunos nas avaliações da disciplina

\begin{tabular}{|l|c|c|}
\hline \multicolumn{1}{|c|}{ Capítulo/Atividade } & Desempenho & Entregas \\
\hline Cap 1 - Introdução & $90 \%$ & 9 \\
\hline Cap 2 - Camada Física & $81 \%$ & 8 \\
\hline Cap 3 - Camada de Enlace & $78 \%$ & 9 \\
\hline Cap 4 - Camada de Rede (Simulador: Rede Local) & $\mathbf{9 4 \%}$ & $\mathbf{7}$ \\
\hline Cap 4 - Camada de Rede (Simulador: Roteamento) & $\mathbf{6 1 \%}$ & $\mathbf{5}$ \\
\hline Cap 5 - Camadas de transporte e de aplicação & $85 \%$ & 10 \\
\hline
\end{tabular}

Fonte: (Próprio autor) 
A análise destes dados permite comentar que esse propósito de "fazer funcionar no simulador", com cada aluno sendo alocado a um conjunto próprio de parâmetros (os números IP's das máquinas) e com o simulador sem o recurso de salvar a simulação, todos estes fatores permitiram dificultar ou talvez evitar eventuais cópias de trabalhos ou outras práticas inapropriadas no processo de avaliação da aprendizagem. Vale destacar que pelo regimento do ERE na instituição não era permitida a avaliação em conexões síncronas, por isso o uso do simulador também foi um avanço neste aspecto de avaliação da aprendizagem em relação às outras formas de avaliação como resolução de exercícios e provas. O número de entregas e notas inferiores indicam um melhor nível de exigência para o aluno.

\subsection{Resultados sobre a percepção e satisfação dos alunos no uso do simulador}

Além de avaliar o nível de dificuldade pelo teste de usabilidade, houve a aplicação dos questionários (vide metodologia SUS) para uma análise tanto da facilidade como do nível de satisfação.

Para avaliar a facilidade (ou dificuldade do uso) questões como "Achei o sistema fácil de usar?", "Foi fácil encontrar a informação que eu precisava?" foram usadas juntamente com as "questões invertidas" que perguntam o oposto, por exemplo "Achei o sistema desnecessariamente complexo" ou "Eu preciso aprender um monde coisas para usar o simulador", esta mescla melhora a qualidade das respostas. Cada pergunta pode ter como resposta discordo completamente, discordo, neutro, concordo e concordo completamente.

As respostas para estas questões foram favoráveis, como amostra de exemplo, a questão "Acho que a maioria dos alunos usaria este sistema com facilidade" no curso técnico teve 5 respostas "concordo" e 2 respostas "neutro". Na pós-graduação um aluno respondeu "concordo completamente" e 2 alunos, "concordo". Ainda sobre facilidade, em outra pergunta "Achei o sistema desnecessariamente complexo", na pós-graduação todos "discordaram completamente" e no curso técnico um aluno "discordou completamente", 5 "discordaram" e outro foi "neutro". As outras questões tiveram respostas em torno destes padrões indicando que os alunos de fato perceberam o sistema como fácil de usar. Isso corroborou os outros resultados discutidos anteriormente.

Além da facilidade, para discussão acerca do grau de satisfação ao usar o sistema, o questionário conta com questões como "Acho que gostaria de usar este sistema com frequência" ou "a interface do sistema é agradável". Por exemplo, para a primeira questão, no curso técnico 5 alunos responderam que "concordavam" e 2 foram "neutros". Na pósgraduação 2 responderam que "concordavam completamente" e outro foi "neutro". Outras questões tinham respostas em mesmos padrões, indício de que a experiência com o simulador foi agradável.

Existe um trato matemático que permite computar o indicador geral de todas respostas. Cada resposta recebe um valor de 0 a 4 e as "questões invertidas" são algebricamente invertidas e todo resultado final é normalizado para se ter um valor na escala de 0 a 100\% (SAURO e LEWIS, 2012). Existe uma escala na metodologia SUS para estes valores que vai do pior imaginável ( 0 a $25 \%$ ) até melhor imaginável ( $85 \%$ a $100 \%)$. Na turma de pós-graduação este indicador foi de $79 \%$ equivalente a um conceito de "Bom" e para a turma do curso técnico o valor do indicador foi de $69 \%$, conceito "Ok".

\section{CONSIDERAÇÕES FINAIS}

Este relato mostrou a aplicação de um simulador para o ensino de Redes de Computadores em uma turma do ensino técnico profissionalizante. Se na engenharia e 
outras áreas o uso de simuladores é motivado pela economia de recursos na montagem de laboratórios ou consumo de materiais e pela segurança no treinamento em cenários de risco, neste trabalho o uso do ambiente em questão foi providencial para minimizar perdas em um modelo de Ensino Remoto Emergencial por conta da pandemia. Diante da inviabilidade de explorar o manuseio físico de equipamentos conseguiu-se pelo menos tratar a montagem, configuração e teste de redes de computadores virtualmente com boa exploração de aspectos lógicos de funcionamento. $E$ isso foi melhor do que uma proposta inicial de tratar os laboratórios apenas com vídeos demonstrativos.

Os resultados podem ser discutidos sob duas perspectivas. Em uma primeira mais direta sobre a aplicação do simulador na turma, os dados levantados sobre o nível de dificuldade e o grau de satisfação dos alunos, bem como os resultados de atividades avaliativas mostraram a boa aceitação e utilidade do simulador no processo de ensino e aprendizagem.

A segunda perspectiva é proveniente da reflexão sobre o processo de planejamento e gestão do uso do simulador. Diante dos desafios e incertezas do cenário tais como as adaptações para o modelo remoto, o início em uma nova instituição, o ensino em uma modalidade diferente de suas experiências anteriores, diante dessas situações o professor precisou de uma postura mais prudente e de conceber estratégias mais sistemáticas. Dentre as ações organizadas vale citar: uma experiência prévia em uma turma mais avançada de pós-graduação, o uso de técnicas de experiência do usuário como personas, cenários, teste de usabilidade e avaliação de satisfação, atividades avaliativas bem direcionadas, correções mais estratificadas e investigativas. Isso resultou em boas reflexões e uma melhor gestão de todo o processo para que os resultados fossem satisfatórios e percebeu-se ao final que isso pode ser replicado para o uso de outros simuladores em outras disciplinas.

Enfim, seja pelos resultados do uso do simulador na turma, seja pelas lições aprendidas na condução das estratégias, esta experiência proporcionou um amadurecimento do professor em sua função. E talvez esse tenha sido o resultado mais significativo, pelas reverberações que pode provocar em novas disciplinas e turmas com novos simuladores e tecnologias.

\section{REFERÊNCIAS}

CISCO NETWORKING ACADEMY. Cisco Packet Tracer. Disponível em: <https://www.netacad.com/pt-br/courses/packet-tracer >. Acesso em: 15 abr 2021.

FARIAS, Flávio Fernando França et al. A utilização dos recursos educacionais do NI MULTISIM LIVE e PSIM para a introdução de simulações em emetrônica de potência. XLVIII Congresso Brasileiro de Educação em Engenharia, Evento On-line, 2020.

GUOQIANG, Chen. Levels of application of computer simulation in engineering disciplines education. 2nd International Conference on Education Technology and Computer, ICETC, Shangai, China, 2010.

MATTA, Cláudia Eliane da; RODRIGUES, Alessandra; LIMA, Rodrigo Silva. Percepções de estudantes e docentes sobre o Regime de Tratamento Excepcional para cursos de engenharia. XLVIII Congresso Brasileiro de Educação em Engenharia, Evento On-line, 2020 . 
MIKROYANNIDIS, Alexander et al. PT Anywhere: a mobile environment for practical learning of network engineering. Interactive Learning Environments, 1-15, 2018.

PT Anywhere. PT Anywhere network simulation. Disponível em: <https://ptanywhere.kmi.open.ac.uk/>. Acesso em: 22 fev 2021.

SAURO, Jeff; LEWIS, James R. Quantifying the user experience: Practical statistics for user research. Waltham: Elsevier (Morgan Kaufmann), 2012.

SILVA, Hudson Henrique da. Desenvolvendo um simulador em escala para ensino na área nuclear. XLVIII Congresso Brasileiro de Educação em Engenharia, Evento On-line, 2020.

SILVA, Rodrigo R. T. et al. Uso do Cisco Packet Tracer como ferramenta no ensinoaprendizagem de Redes de Computadores no IFRN - Campus Mossoró. ScientiaTec: Revista de Educação, Ciência e Tecnologia do IFRS, v.6, n.2, p: 67-78. 2019.

\title{
THE USE OF A SIMULATOR FOR PRACTICES IN A DISCIPLINE OF COMPUTER NETWORKS IN AN EMERGENCY REMOTE TEACHING
}

\begin{abstract}
This work reports an experience of using a simulator for a discipline of computer networks given the impossibility of face-to-face classes in laboratories due to the Covid-19 pandemic. In addition to dealing with an Emergency Remote Education (ERE) model, the lecturer also had other challenges, such as teaching in a new modality (technical education) and in a new region, this required a prudent and well-planned adoption of the technology. At first the simulator was a case study in a subject of Systems Usability in a postgraduate course and then it was applied to the target class of technical education. The results from usability tests and other user experience techniques were satisfactory and point to a potential application of this strategy to minimize losses and explore other alternatives in the teaching and learning process.
\end{abstract}

Keywords: Simulator, Computer Networks, Emergency Remote Education, User Experience. 